\title{
Truncated Life Test Plans for Economic Reliability Based on Four-Parametric Burr Distribution
}

\author{
Ramkumar Balan and Sajana Kunjunni \\ Department of Statistics, St. Thomas' College, Thrissur, Kerala, India \\ Correspondence should be addressed to Ramkumar Balan; rktmidhuna@gmail.com
}

Received 1 June 2013; Revised 1 October 2013; Accepted 8 October 2013

Academic Editor: Tamer Eren

Copyright (C) 2013 R. Balan and S. Kunjunni. This is an open access article distributed under the Creative Commons Attribution License, which permits unrestricted use, distribution, and reproduction in any medium, provided the original work is properly cited.

Burr distribution is considered as a probability model for the lifetime of products. Reliability test plans are those sampling plans in which items from a lot are put to test to make conclusions on the estimate of life, and hence acceptance or rejection of the submitted lot is done. A test plan designs the termination time of the experiment and the termination number for a given sample size and producer's risk. Tables and graphs were provided for certain specific values of designs, and it is useful to verify the optimum reliability test plan realized by Burr distributions.

\section{Introduction}

Reliability study plays a vital role in the quality control, and it can save time and money by realizing early conclusions. If a genuine product (reaching defined life) is rejected on the basis of sample information it is called Type-1 error. On the other hand, if an ingenuine product (not reaching defined life) is accepted by the consumer, then it is called Type-2 error. The decision to accept or reject a lot is subjected to the risks associated with these errors. The procedure is termed as "reliability test plan" or "acceptance sampling based on life test" [1].

Tailed probability distributions are the basis of reliability test plans. These distributions are used to find the reliability sampling plans which will be more economical for the experimenter. Kantam developed a detailed study on life tests based on log-logistic distribution [2]. Rosaiah and Kantam used Inverse Rayleigh distribution to present acceptance sampling [3]. Kantam et al. introduced economic reliability test plan for log-logistic distribution [4], and Aslam and Shahbaz considered generalized exponential distribution to explain economic reliability test plan [5]. Aslam also presented economic reliability test for a generalized Rayleigh Distribution [6]. Rao et al. explained the economic reliability test plan on the basis of Marshall-Olkin extended exponential distribution [7]. Rao et al. considered reliability test plans for
type-II exponentiated log-logistic distribution [8]. Mugahal et al. introduced economic reliability group acceptance sampling plans for lifetimes, a Marshall-Olkin extended distribution [9]. Aslam et al. considered generalized exponential distribution to explain time truncated acceptance sampling [10].

It is found that a null hypothesis about scale parameter such as "the scale parameter is greater than or equal to a specified value" is equivalent to establish that the "average life of a product realized by a given scaled density exceeds the specified average life." Acceptance of this hypothesis by a test procedure is equivalent to getting the sample lifetime echoing the lot quality, and the rejection of hypothesis implies that the lot is a bad.

Ramkumar and Sajana [11] had designed a reliability test plan on four-parametric Burr distribution showing the minimum termination time at a prefixed risk, and this study tries to develop an economic sampling plan under the same assumptions. To verify the efficacy of economic sampling plans, a comparative study of the plans was made by finding the minimum termination time and the acceptance numbers.

General definition of four-parameter Burr distribution and the method of finding the minimum sample size are described in Section 2. The rest of the paper is organized as follows. Section 3 describes the method of finding operating characteristic. An example for illustrating the difference 


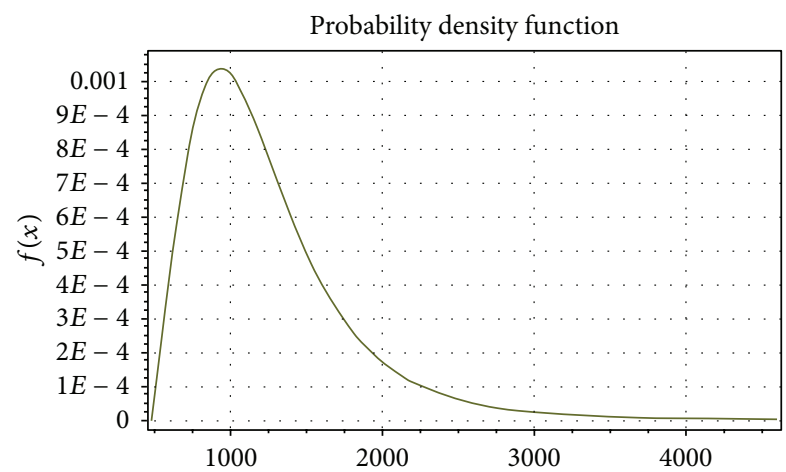

FIGURE 1: The graph of the probability density function of fourparameter Burr distribution of parameters $\gamma=500, \beta=1000, k=2$, and $\alpha=2$.

between these two approaches is given in Section 4. Comparative studies between the two sampling plans were discussed in Section 5, and conclusions were drawn and presented in Section 6.

\section{The Sampling Plan}

Assume that the lifetime of a product follows four-parametric Burr distribution. The cumulative distribution function and probability distribution function of the Burr distribution are given by

$$
F(x ; \gamma, \beta, k, \alpha)=1-\left(1+\left(\frac{x-\gamma}{\beta}\right)^{\alpha}\right)^{-k},
$$

$$
\text { for } \gamma, \beta, k, \alpha>0, x>\gamma \text {. }
$$

Let $t=x-\gamma$, then the CDF becomes

$$
F(t ; \beta, k, \alpha)=1-\left(1+\left(\frac{t}{\beta}\right)^{\alpha}\right)^{-k} \text { for } t, \beta, k, \alpha>0
$$

Also the probability density function of four-parameter Burr distribution is

$$
\begin{aligned}
f(x ; \gamma, \beta, k, \alpha)= & \frac{\alpha k((x-\gamma) / \beta)^{\alpha-1}}{\beta\left(1+((x-\gamma) / \beta)^{\alpha}\right)^{k+1}}, \\
& \text { for } \gamma, \beta, k, \alpha>0, x>\gamma .
\end{aligned}
$$

The graphical representation of probability density function of four-parameter Burr distribution for specified parameters $\gamma=500, \beta=1000, k=2$, and $\alpha=2$ is shown in Figure 1 .

Consider a null hypothesis

$$
H_{0}: \beta>\beta_{0} .
$$

Let the lifetime of a product follows the above Burr distribution with eventual failures; the above hypothesis becomes the average life of the product. If $H_{0}$ is accepted on the basis of sample lifetime data, one may conclude that the submitted lot has a better average lifetime than the specified quality. Hence, the lot can be termed as good and accepted.

In reliability test plans based on Burr distribution, the minimum sample size to make a decision about the lot for a given waiting time in terms of $\beta_{0}$ (i.e., $t / \beta_{0}$ ), acceptance number $c$, and some risk probability (say $\alpha^{*}$ ) for a specified $\beta_{0}$ of $\beta$ which is the probability of detecting $c$ is required.

If the number of failures is less than or equal to the acceptance number $c$ in a sample of size $n$, the lot is accepted and hence the probability of accepting the lot:

$$
\sum_{i=0}^{c}\left(\begin{array}{c}
n \\
i
\end{array}\right) p_{0}^{i}\left(1-p_{0}\right)^{n-i}
$$

where $p_{0}=1-\left(1+\left(t / \beta_{0}\right)^{\alpha}\right)^{-k}$.

For $\beta>\beta_{0}$, the above probability of acceptance will increase. Therefore, if $\alpha^{*}$ is a prefixed risk, probability of minimum risk is

$$
\sum_{i=0}^{c}\left(\begin{array}{c}
n \\
i
\end{array}\right) p_{0}^{i}\left(1-p_{0}\right)^{n-i} \geq \alpha^{*} .
$$

For a given $\beta_{0}$ and $t / \beta_{0}$, this is a single inequality in two unknowns $n$ and $c$ for the assumed parameters $\alpha$ and $k$. The above inequality can be solved for $n$ with successive values of $c$ from zero. The minimum values of $n$ which satisfies the inequality (6) are for $\alpha^{*}=0.01,0.05,0.10$, and 0.25 and $t / \beta_{0}=0.306,0.413,0.521,0.841,1.055,1.483$, and 1.911 at $\gamma=$ $500, k=2$, and $\alpha=2$, given in Table 1 . The minimum value of $n$ satisfies the binomial approximations which are obtained for the combination producers risk $\left(1-\alpha^{*}\right)$ and operating ratio $t / \beta_{0}$.

Fixing " $n$ " and " $r$ " be a natural number less than sample size $(n)$. The acceptance criteria can be restated as follows.

(1) Put " $n$ " items on test.

(2) Stop the process if $r=(c+1)$ th failure occurs before $t$ and the lot is rejected.

One may be interested that the probability of acceptance should be as large as possible for a given $\beta=\beta_{0}$, and specify " $n$ " as a multiple of " $r$ " $(r=1,2 \ldots)$. Then,

$$
L\left(p_{0}\right)=\sum_{i=0}^{c}\left(\begin{array}{c}
n \\
i
\end{array}\right) p_{0}^{i}\left(1-p_{0}\right)^{n-i} \geq \alpha^{*} .
$$

Given the values of $n$ (where $n=r * k$ ), $r$, and $k$ (integer), the above inequality can be solved for " $p_{0}$ " using cumulative probabilities of binomial distribution. Then the values of " $p_{0}$ " can be used in the cumulative density function for $\alpha=2$ to find the values of $t / \beta_{0}$. With the choices of $r(r=1,2 \ldots, k)$ and $\alpha$, the termination ratio could be found satisfying the above inequality. The termination ratios are given in Table 2 for various values of $r$ and $n$.

\section{Operating Characteristic Function}

If unknown lifetime of the product deviates from the specified lifetime, it should result in a considerable change in 
TABLE 1: Minimum sample size for the specified ratio $t / \beta_{0}$, confidence level $1-\alpha^{*}$, acceptance number $c, k=2$, and $\alpha=2$ using binomial approximation.

\begin{tabular}{|c|c|c|c|c|c|c|c|c|c|}
\hline \multirow{2}{*}{$1-\alpha^{*}$} & \multirow{2}{*}{$c$} & \multicolumn{8}{|c|}{$t / \beta_{0}$} \\
\hline & & 0.306 & 0.413 & 0.521 & 0.627 & 0.841 & 1.055 & 1.483 & 1.911 \\
\hline 0.75 & 0 & 7 & 4 & 3 & 2 & 1 & 1 & 1 & 1 \\
\hline 0.75 & 1 & 15 & 9 & 6 & 4 & 3 & 2 & - & - \\
\hline 0.75 & 2 & 22 & 13 & 9 & 7 & 4 & 3 & - & - \\
\hline 0.75 & 3 & 30 & 17 & 12 & 9 & 6 & 5 & - & - \\
\hline 0.75 & 4 & 37 & 22 & 15 & 11 & 8 & 6 & - & - \\
\hline 0.75 & 5 & 44 & 26 & 18 & 13 & 9 & 8 & - & - \\
\hline 0.75 & 6 & 50 & 30 & 21 & 16 & 11 & 9 & - & - \\
\hline 0.75 & 7 & 57 & 34 & 23 & 18 & 13 & 10 & - & - \\
\hline 0.75 & 8 & 64 & 38 & 26 & 20 & 14 & 12 & - & - \\
\hline 0.75 & 9 & 71 & 42 & 29 & 22 & 16 & 13 & - & - \\
\hline 0.75 & 10 & 77 & 46 & 32 & 25 & 18 & 14 & - & - \\
\hline 0.9 & 0 & 12 & 7 & 4 & 3 & 2 & 1 & 1 & 1 \\
\hline 0.9 & 1 & 22 & 12 & 8 & 6 & 4 & 3 & 2 & 2 \\
\hline 0.9 & 2 & 30 & 17 & 12 & 9 & 6 & 4 & 3 & 3 \\
\hline 0.9 & 3 & 38 & 22 & 15 & 11 & 7 & 6 & 4 & 4 \\
\hline 0.9 & 4 & 46 & 27 & 18 & 14 & 9 & 7 & 6 & 5 \\
\hline 0.9 & 5 & 54 & 32 & 22 & 16 & 11 & 9 & 7 & 6 \\
\hline 0.9 & 6 & 61 & 36 & 25 & 19 & 13 & 10 & 8 & 7 \\
\hline 0.9 & 7 & 69 & 41 & 28 & 21 & 15 & 12 & 9 & 8 \\
\hline 0.9 & 8 & 76 & 45 & 31 & 24 & 16 & 13 & 10 & 9 \\
\hline 0.9 & 9 & 84 & 49 & 34 & 26 & 18 & 14 & 12 & 10 \\
\hline 0.9 & 10 & 91 & 54 & 37 & 28 & 20 & 16 & 13 & 12 \\
\hline 0.95 & 0 & 16 & 9 & 6 & 4 & 2 & 2 & 1 & 1 \\
\hline 0.95 & 1 & 27 & 15 & 10 & 7 & 5 & 3 & 2 & 2 \\
\hline 0.95 & 2 & 36 & 21 & 14 & 10 & 7 & 5 & 4 & 3 \\
\hline 0.95 & 3 & 44 & 26 & 17 & 13 & 8 & 6 & 5 & 4 \\
\hline 0.95 & 4 & 53 & 31 & 21 & 16 & 10 & 8 & 6 & 5 \\
\hline 0.95 & 5 & 61 & 36 & 24 & 18 & 12 & 10 & 7 & 6 \\
\hline 0.95 & 6 & 69 & 40 & 27 & 21 & 14 & 11 & 9 & 8 \\
\hline 0.95 & 7 & 77 & 45 & 31 & 23 & 16 & 13 & 10 & 9 \\
\hline 0.95 & 8 & 84 & 50 & 34 & 26 & 18 & 14 & 11 & 10 \\
\hline 0.95 & 9 & 92 & 54 & 37 & 28 & 19 & 15 & 12 & 11 \\
\hline 0.95 & 10 & 99 & 59 & 40 & 31 & 21 & 17 & 13 & 12 \\
\hline 0.99 & 0 & 24 & 14 & 9 & 6 & 4 & 3 & 1 & 1 \\
\hline 0.99 & 1 & 37 & 21 & 14 & 10 & 6 & 5 & 3 & 2 \\
\hline 0.99 & 2 & 47 & 27 & 18 & 13 & 8 & 6 & 4 & 4 \\
\hline 0.99 & 3 & 57 & 33 & 22 & 16 & 11 & 8 & 6 & 5 \\
\hline 0.99 & 4 & 66 & 38 & 26 & 19 & 13 & 10 & 7 & 6 \\
\hline 0.99 & 5 & 75 & 44 & 29 & 22 & 15 & 12 & 8 & 7 \\
\hline 0.99 & 6 & 84 & 49 & 33 & 25 & 17 & 13 & 10 & 8 \\
\hline 0.99 & 7 & 92 & 54 & 37 & 27 & 18 & 14 & 11 & 9 \\
\hline 0.99 & 8 & 100 & 59 & 40 & 30 & 20 & 16 & 12 & 11 \\
\hline 0.99 & 9 & 109 & 64 & 43 & 33 & 22 & 17 & 13 & 12 \\
\hline 0.99 & 10 & 117 & 69 & 47 & 35 & 24 & 19 & 15 & 13 \\
\hline
\end{tabular}

the probability of acceptance of the lot based on the sampling plan. Hence, the probability of acceptance can be regarded as a function of the deviation of specified average lifetime from

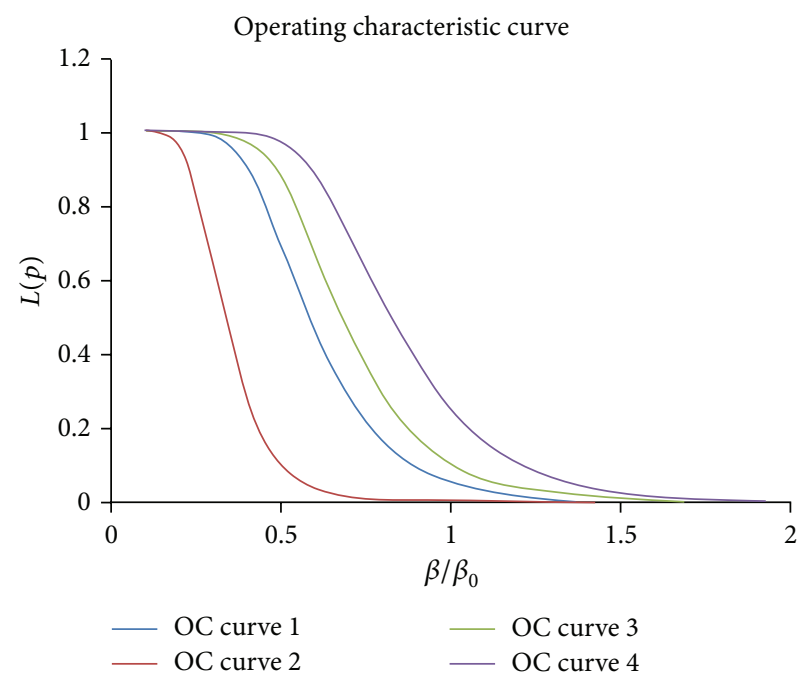

FIgURE 2: The operating characteristic curve of Table 3.

the true average lifetime. This function is called operating characteristic function of the sampling plan. Specifically if $F(t)$ is the cumulative distribution function of the lifetime random variable of the product, " $\beta_{0}$ " corresponds to a specified life.

Thus,

$$
\begin{aligned}
& L(p)=L\left(F\left(\frac{t}{\beta}\right)\right), \\
& F\left(\frac{t}{\beta}\right)=F\left(\frac{t / \beta_{0}}{\beta / \beta_{0}}\right),
\end{aligned}
$$

where " $\beta$ " corresponds to true but unknown average life. The ratio $\beta / \beta_{0}$ in the right hand side of the above equation can be taken as a measure of changes between true and specified life. For instance, $\beta / \beta_{0}<1$ implies that the true mean life is less than the declared life leading to less acceptance probability or more failure risk. Similarly, $\beta / \beta_{0}>1$ implies more acceptance probability or less failure risk. Hence, giving a set of hypothetical values, say $\beta / \beta_{0}=0.1,1.9 \ldots$, the corresponding acceptance probability for the given sampling plan is determined. For selected sampling plans, the operating characteristic (OC) values were given in Table 3. The OC curves for different values of $n$ as given in Table 3 are shown in Figure 2.

\section{Example}

Consider a simulated problem associated with failure times of bulbs whose lifetime follows four-parameter Burr distribution with $\gamma=500, k=2$, and $\alpha=2$. This data can be regarded as an ordered sample of size $n=10$ with observations 794, 1284, 1087, 1369, 2206, 1346, 939, 1578, 953, and 1092 . Goodness of fit details for this sample is shown in Table 5.

4.1. Illustration of Example Using Reliability Test Plan. Let the required average life time be 1000 hours and the testing time 
TABLE 2: Life test termination time as a ratio of scale parameter $\left(t / \beta_{0}\right)$ for Burr distribution with $\alpha=2$ and $k=2$.

\begin{tabular}{|c|c|c|c|c|c|c|c|c|c|}
\hline$n$ & $2 r$ & $3 r$ & $4 r$ & $5 r$ & $6 r$ & $7 r$ & $8 r$ & $9 r$ & $10 r$ \\
\hline$r$ & \multicolumn{9}{|c|}{$\alpha^{*}=0.05$} \\
\hline 1 & 0.10989 & 0.09147 & 0.07928 & 0.07091 & 0.06463 & 0.05989 & 0.05632 & 0.05196 & 0.04978 \\
\hline 2 & 0.22796 & 0.17984 & 0.15388 & 0.13652 & 0.12391 & 0.11442 & 0.10656 & 0.10062 & 0.09496 \\
\hline 3 & 0.29303 & 0.22842 & 0.19398 & 0.17164 & 0.15483 & 0.14292 & 0.13294 & 0.12564 & 0.11873 \\
\hline 4 & 0.33525 & 0.25927 & 0.21873 & 0.19372 & 0.17483 & 0.16096 & 0.14978 & 0.13998 & 0.13286 \\
\hline 5 & 0.36551 & 0.28128 & 0.23661 & 0.20887 & 0.18892 & 0.17342 & 0.16182 & 0.15172 & 0.14368 \\
\hline 6 & 0.38747 & 0.29698 & 0.24976 & 0.21963 & 0.19851 & 0.18285 & 0.17047 & 0.16013 & 0.14999 \\
\hline 7 & 0.40514 & 0.30944 & 0.25994 & 0.22871 & 0.20673 & 0.19054 & 0.17634 & 0.16642 & 0.15713 \\
\hline 8 & 0.42012 & 0.31963 & 0.26846 & 0.23654 & 0.21382 & 0.19647 & 0.18266 & 0.17157 & 0.16216 \\
\hline 9 & 0.43194 & 0.32842 & 0.27569 & 0.24252 & 0.21906 & 0.20119 & 0.18698 & 0.17564 & 0.16574 \\
\hline 10 & 0.44252 & 0.33537 & 0.28147 & 0.24763 & 0.22352 & 0.20516 & 0.19096 & 0.17914 & 0.16962 \\
\hline$r$ & \multicolumn{9}{|c|}{$\alpha^{*}=0.01$} \\
\hline 1 & 0.02010 & 0.01360 & 0.01200 & 0.01098 & 0.00916 & 0.00848 & 0.00791 & 0.00747 & 0.00710 \\
\hline 2 & 0.09164 & 0.06510 & 0.05642 & 0.04896 & 0.04479 & 0.04107 & 0.03884 & 0.03604 & 0.03422 \\
\hline 3 & 0.14044 & 0.11112 & 0.09430 & 0.08341 & 0.07556 & 0.06919 & 0.06479 & 0.06069 & 0.05834 \\
\hline 4 & 0.18949 & 0.14985 & 0.12321 & 0.10834 & 0.09862 & 0.09019 & 0.08455 & 0.07952 & 0.07486 \\
\hline 5 & 0.22011 & 0.17143 & 0.14521 & 0.12812 & 0.11541 & 0.10727 & 0.09892 & 0.09345 & 0.08813 \\
\hline 6 & 0.24937 & 0.19142 & 0.16248 & 0.14337 & 0.13001 & 0.11901 & 0.11075 & 0.10499 & 0.09841 \\
\hline 7 & 0.27425 & 0.21021 & 0.17672 & 0.15591 & 0.140412 & 0.12999 & 0.12033 & 0.11296 & 0.10732 \\
\hline 8 & 0.29307 & 0.22386 & 0.18802 & 0.16573 & 0.14988 & 0.13776 & 0.12825 & 0.12049 & 0.11429 \\
\hline 9 & 0.31030 & 0.23574 & 0.19901 & 0.17457 & 0.15773 & 0.14524 & 0.13537 & 0.12726 & 0.12006 \\
\hline 10 & 0.32198 & 0.24562 & 0.20684 & 0.18268 & 0.16501 & 0.15201 & 0.14098 & 0.13232 & 0.13011 \\
\hline
\end{tabular}

TABLE 3: Operating characteristic values for the proposed plan based on Burr distribution with $k=2$ and $\alpha=2$ for specified values of terminating number $r$ and producer's risk $\alpha^{*}=0.05,0.01,0.10$, and 0.25 .

\begin{tabular}{|c|c|c|c|c|}
\hline$\beta / \beta_{0}$ & $\begin{array}{c}(\text { OC curve } 1) \\
r=4, \alpha^{*}=0.05 \\
n=8, t / \beta_{0}=0.33525\end{array}$ & $\begin{array}{c}(\text { OC curve } 2) \\
r=4, \alpha^{*}=0.01 \\
n=8, t / \beta_{0}=0.18949\end{array}$ & $\begin{array}{c}(\text { OC curve } 3) \\
r=4, \alpha^{*}=0.10 \\
n=12, t / \beta_{0}=0.29388\end{array}$ & $\begin{array}{c}(\text { OC curve } 4) \\
r=4, \alpha^{*}=0.25 \\
n=12, t / \beta_{0}=0.35692\end{array}$ \\
\hline 0.1 & 1 & 1 & 1 & 1 \\
\hline 0.2 & 1 & 0.958 & 1 & 1 \\
\hline 0.3 & 0.99 & 0.612 & 0.999 & 1 \\
\hline 0.4 & 0.9 & 0.258 & 0.978 & 0.998 \\
\hline 0.5 & 0.688 & 0.095 & 0.862 & 0.97 \\
\hline 0.6 & 0.451 & 0.035 & 0.652 & 0.872 \\
\hline 0.7 & 0.269 & 0.014 & 0.436 & 0.706 \\
\hline 0.8 & 0.154 & 0.006 & 0.272 & 0.521 \\
\hline 0.9 & 0.087 & 0.003 & 0.163 & 0.362 \\
\hline 1.0 & 0.049 & 0.001 & 0.097 & 0.242 \\
\hline 1.1 & 0.028 & 0.0006 & 0.058 & 0.159 \\
\hline 1.2 & 0.017 & 0.0003 & 0.035 & 0.103 \\
\hline 1.3 & 0.009 & 0.0002 & 0.022 & 0.068 \\
\hline 1.4 & 0.006 & 0.0001 & 0.013 & 0.044 \\
\hline 1.5 & 0.004 & 0.00005 & 0.009 & 0.029 \\
\hline 1.6 & 0.002 & 0.00004 & 0.006 & 0.02 \\
\hline 1.7 & 0.002 & 0.00002 & 0.004 & 0.013 \\
\hline 1.8 & 0.001 & 0.00001 & 0.002 & 0.009 \\
\hline 1.9 & 0.001 & 0.000009 & 0.002 & 0.006 \\
\hline
\end{tabular}


TABLE 4: Proportions of life test termination time $\left(t / \beta_{0}\right)$ for the present sampling plans and reliability test plan with producer's risk $\alpha^{*}=0.05$, 0.01 .

\begin{tabular}{|c|c|c|c|c|c|c|c|c|c|c|c|c|c|c|c|c|c|c|c|}
\hline & & & & & II & & & & & & & & & & 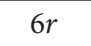 & & & & 西 \\
\hline & \multicolumn{9}{|c|}{$=0.05$} & 1 & \multicolumn{9}{|c|}{-0} \\
\hline & & & & & 0.065 & & & & & & & & & & & & & & \\
\hline & 55 & 792 & 627 & 591 & 0. & 483 & 447 & 113 & 392 & & & & & & & & & & 4 \\
\hline & & & & & & & & & & & & & & & & & & & .004 \\
\hline & 0.98 & 734 & 598 & & & o & 0.406 & 370 & 0.357 & & & & & & & & & & 427 \\
\hline & & & & & & & & & & & & & & & & & & & \\
\hline & 0.957 & 684 & 566 & & TIO & to & & & $x$ & & & & & & & & & & 379 \\
\hline & & & & & & & & & & & & & & & & & & & .075 \\
\hline & 0 & 665 & .548 & & & & & & 0.325 & & & & & & & & & & .369 \\
\hline & 0 & & & & & & & & & & & & & & & & & & 0.088 \\
\hline & 0 & & & & & & & & & & & & & & & & & & \\
\hline & & & & & & & & & & & & & & & & & & & 0 \\
\hline & 0.84 & 0.627 & 0.521 & 0.457 & 0.413 & 0 & 0.349 & 5 & 0.309 & & & & & & & & & & 34 \\
\hline & 0.40 & & & & 2 & & & & & & & & & & & & & & 10 \\
\hline & 0.841 & 627 & -5 & 0.451 & 0.401 & 66 & 0.341 & 22 & $E$ & & & & & & & & & & 0.338 \\
\hline & 0.420 & . & 268 & & 0.2 & & & & & & & & & & & & & & 14 \\
\hline & 0.841 & 617 & 500 & 445 & 20 & 0365 & 220 & 317 & 0.298 & & & & & & & & & & 327 \\
\hline & 0.432 & 328 & 276 & 212 & 0210 & 0.201 & 0.187 & 176 & 0166 & & 0. & 0.236 & 0.199 & & & 15 & & & 0.120 \\
\hline & 0.841 & 61 & 50 & 0.43 & 0.391 & 0.3 & 0. & 3 & 4 & & 0.9 & 0.6 & 3 & 0. & & 4 & & 39 & 16 \\
\hline & & 335 & 0.28 & 0.248 & 22 & 0.205 & 0.191 & 0.17 & 0.169 & & 0.322 & 0.246 & 0.207 & 0.183 & 0.165 & 0.152 & 0.141 & 132 & 0 . \\
\hline & & 0.602 & 0.498 & 0.434 & 0.386 & 0.355 & 0.331 & 0.308 & 0.291 & & 0.919 & 0.667 & 0.534 & 0.473 & 0.429 & 0.384 & 0.358 & 0.335 & 0.321 \\
\hline
\end{tabular}

be $t=521$, leading to ratio $t / \beta_{0}=0.521$ with a corresponding sample size $n=10$ and acceptance number $c=1$ obtained from Table 1 , for $1-\alpha^{*}=0.95$. Therefore, the sampling plan for the above sample data is $\left(n=10, c=1, t / \beta_{0}=0.521\right)$. Based on the data, it is to decide whether the lot is accepted or rejected. Accept the product only if the number of failures before 521 hours is less than or equal to 1 .

In the above sample of size 10, there are no failures before the termination time $t=521$ hours and the acceptance number of the plan $c=1$. Therefore, accept the product.

\subsection{Illustration of Example Using Economic Sampling Plan.} From the life test termination in Table 2, corresponding to $r=2(r=c+1)$, for column $5 r$, the value is 0.13652 . As the acceptable average lifetime is 1000 hours (given) for four-parameter Burr distribution, then the termination time is obtained as $t=0.13652 * 1000=136.52=137$ (approximately).

According to the above sampling plan, if the first failure is realized before 137th hour of the test, reject the lot; otherwise, accept the lot. In either case terminating the experiment as soon as the first failure is reached or 137 th hour of the test time is realized whichever is earlier. In the case of acceptance, the assurance is that the average life of the submitted products is at least 1000 hours.

There are no failures before 137th hour, and accept the lot (in the example) by this approach. Thus, for both approaches, the sample size, acceptance number (termination number), the risk probability, and the decision about the lot are the same. The decision on the first approach can be reached only at the 521st hour while in the second approach decision is realized at the 137th hour, showing that the economic sampling plan requires less waiting time.

\section{Comparative Study}

In order to compare the economic sampling plan with reliability test plan, the values are presented for $\alpha=2$, $\alpha^{*}=0.05,0.01$ in Table 4. The entries given in the first row represent economic sampling plan, and the values of the second row show reliability sampling plan. Termination values in the example are taken for $r=2, n=5 r$, and $\alpha^{*}=0.05$ from Table 4 . For any $r, n$, and $\alpha^{*}$, the present test plan gives minimum termination time than reliability test plan saving money and time of experiment

\section{Conclusion}

This paper presents the economic test plan for lifetime of products following four-parameter Burr distribution. The proposed plan suggests a way for achieving optimum reliability test plan for tailed Burr distribution. Comparative study affirms the conclusion that the present test plan works with minimum termination time (waiting time) ensuring minimum experimental cost at more or less same sampling design. 
TABLE 5: Goodness of fit details.

\begin{tabular}{|c|c|c|c|c|c|}
\hline \multicolumn{6}{|c|}{ Kolmogorov-Smirnov } \\
\hline Sample size & & & 10 & & \\
\hline Statistic & & & 0.19705 & & \\
\hline$P$ value & & & 0.76382 & & \\
\hline Rank & & & 33 & & \\
\hline$\alpha$ & 0.2 & 0.1 & 0.05 & 0.02 & 0.01 \\
\hline Critical value & 0.3226 & 0.36866 & 0.40925 & 0.45662 & 0.48893 \\
\hline Reject? & No & No & No & No & No \\
\hline \multicolumn{6}{|c|}{ Anderson-Darling } \\
\hline Sample size & & & 10 & & \\
\hline Statistic & & & 0.43355 & & \\
\hline Rank & & & 30 & & \\
\hline$\alpha$ & 0.2 & 0.1 & 0.05 & 0.02 & 0.01 \\
\hline Critical value & 1.3749 & 1.9286 & 2.5018 & 3.2892 & 3.9074 \\
\hline Reject? & No & No & No & No & No \\
\hline \multicolumn{6}{|c|}{ Chi-squared } \\
\hline Deg. of freedom & & & 1 & & \\
\hline Statistic & & & 0.07696 & & \\
\hline$P$ value & & & 0.78146 & & \\
\hline Rank & & & 28 & & \\
\hline$\alpha$ & 0.2 & 0.1 & 0.05 & 0.02 & 0.01 \\
\hline Critical value & 1.6424 & 2.7055 & 3.8415 & 5.4119 & 6.6349 \\
\hline Reject? & No & No & No & No & No \\
\hline
\end{tabular}

The continuous improvement and review of acceptance sampling plan are important to improve the quality of the products and to ensure customer satisfaction.

\section{Acknowledgment}

The authors hereby extent sincere gratitude to the reviewers for their valuable suggestions for rectification of errors as well as for modification of the format.

\section{References}

[1] A. J. Ducan, Quality Control and Industrial Statistics, Irwin Home Wood III, Toronto, Canada, 5th edition, 1986.

[2] R. R. L. Kantam, K. Rosaiah, and G. S. Rao, "Acceptance sampling based on life tests: log-logistic model," Journal of Applied Statistics, vol. 28, no. 1, pp. 121-128, 2001.

[3] K. Rosaiah and R. R. L. Kantam, "Acceptance sampling based on the inverse Rayleigh distribution," Economic Quality Control, vol. 20, no. 2, pp. 277-286, 2005.

[4] R. R. L. Kantam, G. Srinivasa Rao, and B. Sriram, "An economic reliability test plan: log-logistic distribution," Journal of Applied Statistics, vol. 33, no. 3, pp. 291-296, 2006.

[5] M. Aslam and M. Q. Shahbaz, "Economic reliability test plan, generalized exponential distribution," Journal of Statistics, vol. 14, pp. 52-59, 2007.

[6] M. Aslam, "Economic reliability test generalized rayleigh distribution," Journal of Statistics, pp. 26-35, 2008.

[7] G. S. Rao, M. E. Ghitany, and R. R. L. Kantam, "An economic reliability test plan for Marshall-Olkin extended exponential distribution," Applied Mathematical Sciences, vol. 5, no. 3, pp. 103-112, 2011.

[8] G. S. Rao, R. R. L. Kantam, K. Rosaiah, and S. V. Prasad, "Reliability test plans for type-II exponentiated log-logistic distribution," Journal of Reliability and Statistical Studies, vol. 5, no. 1, pp. 55-64, 2012.

[9] A. Mugahal, M. Aslam, J. Hussain, and A. Rehman, "Economic relibility group acceptance sampling plans for lifetimes a Marshall-Olkin extended distribution," Middle Eastern Finance and Economics, no. 7, 2010.

[10] M. Aslam, D. Kundu, and M. Ahmad, "Time truncated acceptance sampling plans for generalized exponential distribution," Journal of Applied Statistics, vol. 37, no. 4, pp. 555-566, 2010.

[11] T. B. Ramkumr and O. K. Sajana, "Reliability test plan based on Burr distribution," International Journal of Mathematics and Computer Applications Research, vol. 1, no. 2, pp. 28-40, 2011. 


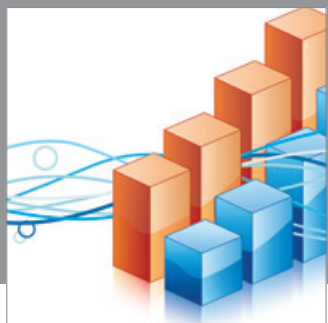

Advances in

Operations Research

mansans

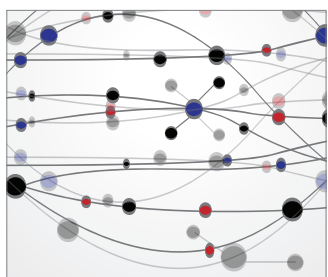

The Scientific World Journal
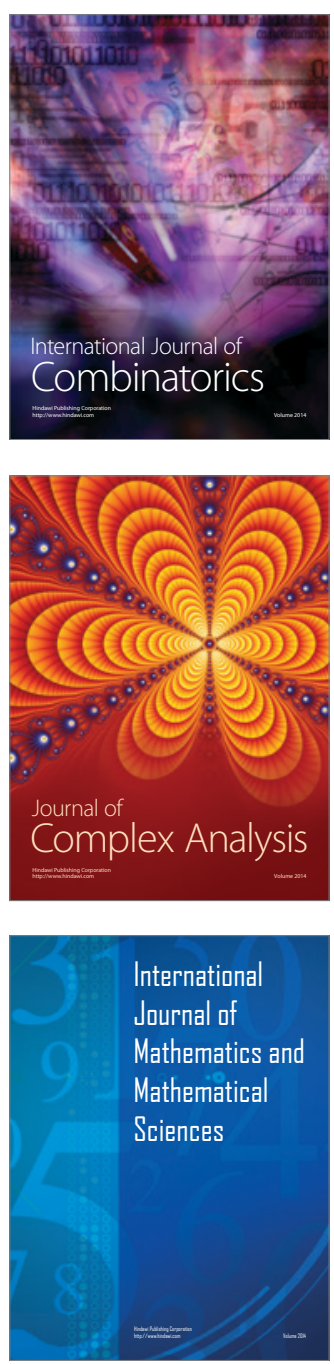
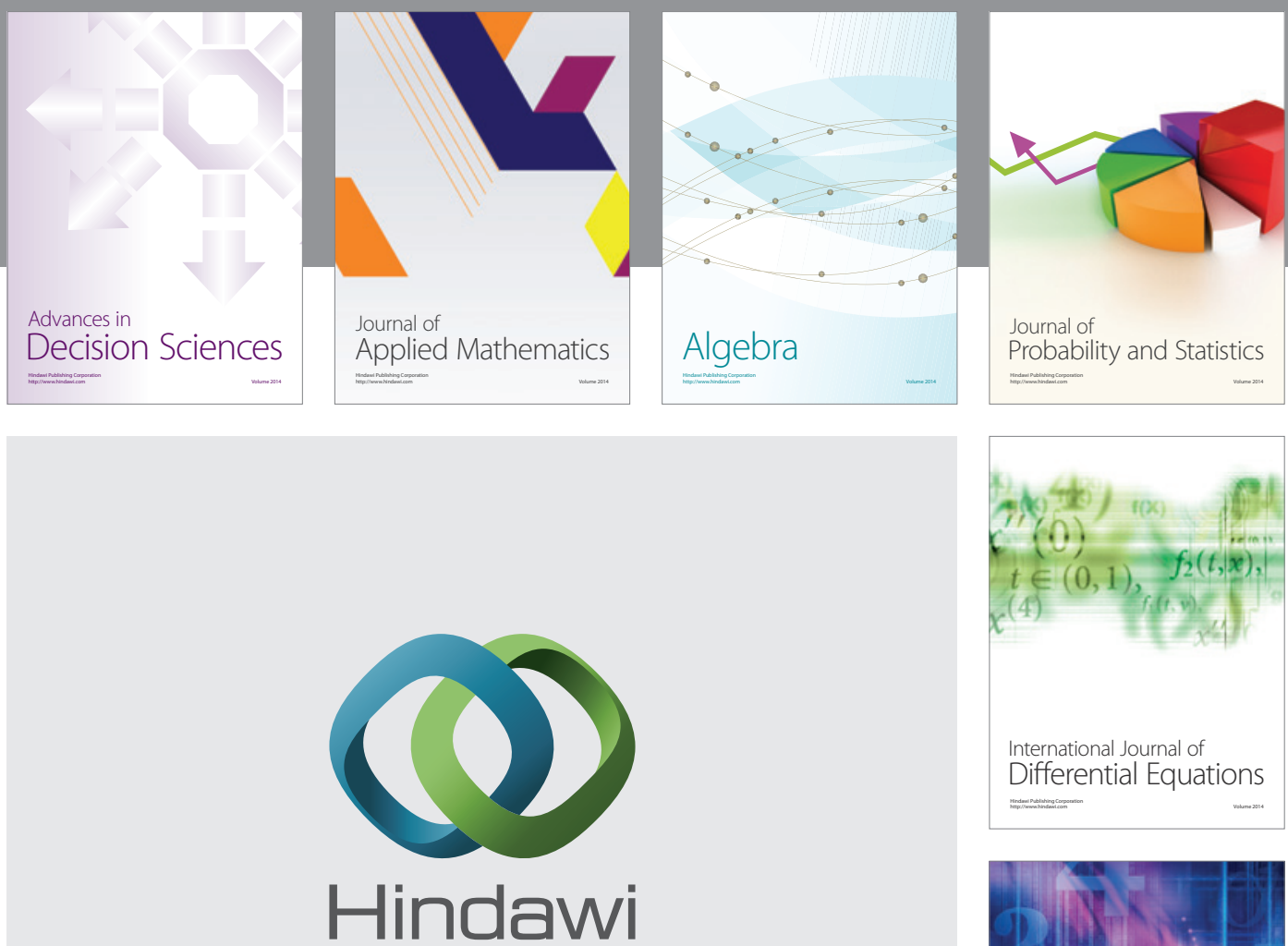

Submit your manuscripts at http://www.hindawi.com
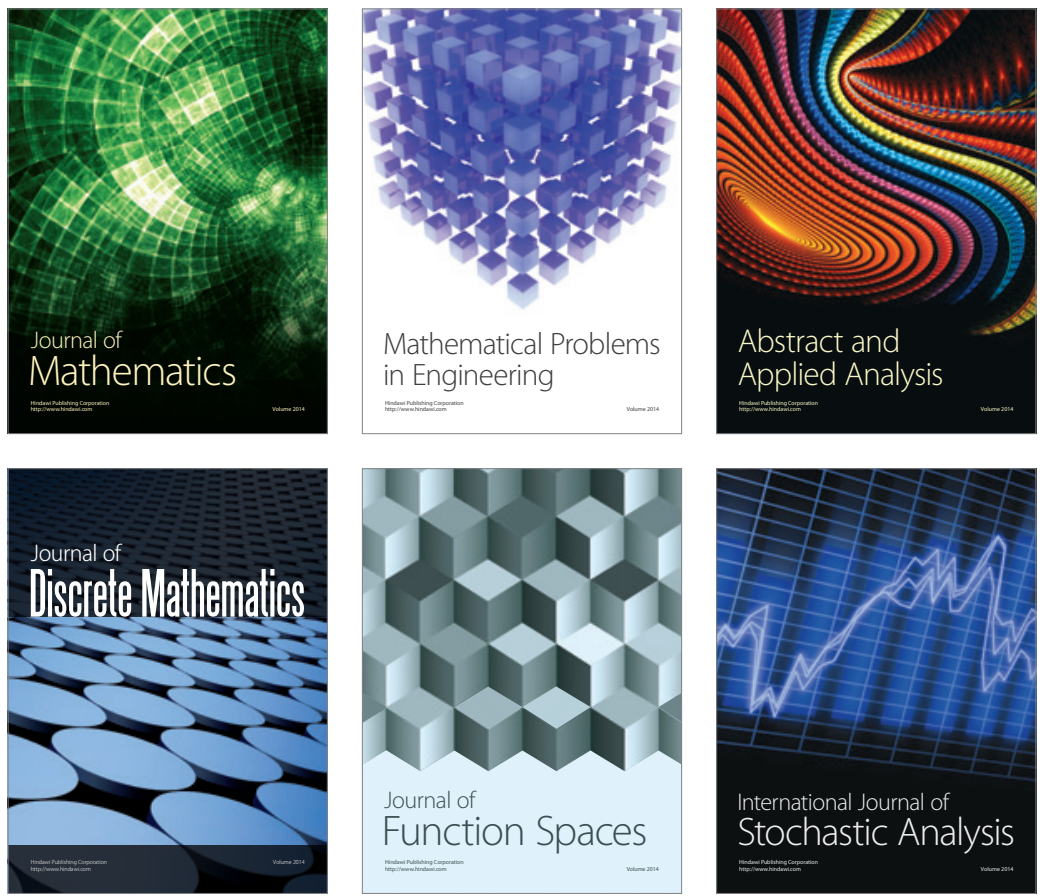

Journal of

Function Spaces

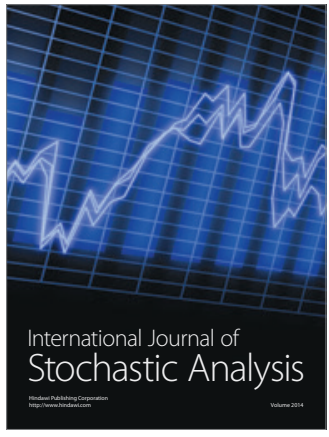

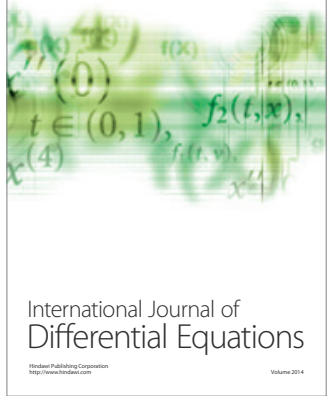
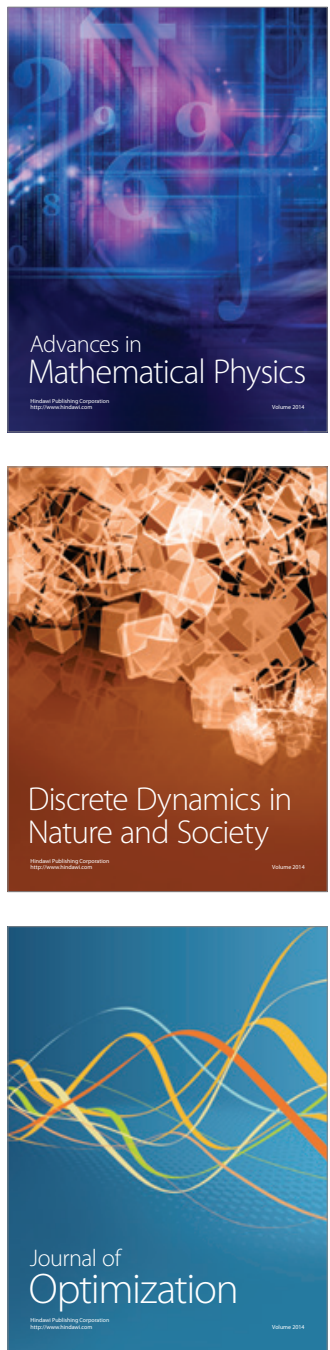